Western University

Scholarship@Western

EXPLORING THE PLACELESSNESS OF READING AMONG OLDER TEENS IN A CANADIAN RURAL MUNICIPALITY

Paulette Rothbauer

Western University, prothba2@uwo.ca

Follow this and additional works at: https://ir.lib.uwo.ca/fimspub

Part of the Library and Information Science Commons, and the Quantitative, Qualitative, Comparative, and Historical Methodologies Commons

Citation of this paper:

Rothbauer, Paulette. "Exploring the placelessness of reading among older teens in a Canadian rural municipality." The Library Quarterly 79.4 (2009): 465-483. 


\title{
EXPLORING THE PLACELESSNESS OF READING AMONG OLDER TEENS IN A CANADIAN RURAL MUNICIPALITY ${ }^{1}$
}

\author{
Paulette Rothbauer ${ }^{2}$
}

\begin{abstract}
Situated in a review of rural, cultural, and youth geographies, this article reports on a qualitative study of the role of reading and libraries in the lives of older rural teenagers. The primary method of data collection was the use of in-depth, flexibly structured interviews with twenty-seven youth between the ages of fifteen and nineteen years, supplemented with data from unobtrusive observation and environmental scanning in a specific geographic locale. Four themes are discussed: the habitual, quotidian reading of teenagers; the shifting visibility of the public library; the Internet and the World Wide Web as a default reading site; and the temporal constraints on reading for pleasure. With the use of ideas informed by cultural geography, the space of nonactive teen readers and the placelessness of reading are explored.
\end{abstract}

\section{Introduction}

The research presented in this article begins with an assumption that cultural geography can help us understand reading practices in a specific geographic locale. It asks questions about the relationships among reading, readers, and place-if place matters, how does it matter, and what evidence do we have that it does? This article begins with a review of how rural library services for youth have been covered in the library and information studies literature, followed by an overview of ideas from the cultural, rural, and youth geographies that have informed this study. Research methods are presented in detail to give a clear picture of how data were collected and analyzed. This is followed by discussion of four major themes related to place that emerge from the data analysis, and in the final section these

1. The author acknowledges the support provided by the Social Sciences and Humanities Research Council of Canada.

2. University of Western Ontario, North Campus Building, Room 224, London, ON N6A 5B7, Canada; E-mail prothba2@uwo.ca.

[Library Quarterly, vol. 79, no. 4, pp. 465-483]

(C) 2009 by The University of Chicago. All rights reserved. 0024-2519/2009/7904-0004\$10.00 
themes are analyzed using ideas of space and place to theorize the habitual reading practices of older teens in a Canadian rural municipality.

The Library as Place, a collection of scholarly essays edited by Gloria J. Leckie and John E. Buschman, published in 2007, gives ample evidence of recent interest within library and information science (LIS) in the study of libraries, using the lenses of geographic thought. In their introduction, the editors write, "A humanistic approach to the library as place enables us to explore questions related to how libraries function as physical places of embodiment in the everyday, how they are understood and used by their clientele, and what symbolic meaning they hold for their community of users" [1, p. 9]. This article explores such themes in the context of everyday reading and library and Internet use among young adults in rural southwestern Ontario, Canada.

Literature Review: Rural Libraries and Cultural, Rural, and Youth Geographies

Four main themes emerge from a review of the small body of literature on rural library services for young people published during the past twentyfive years. There is an emphasis on the difficulties in service provision resulting from changes in demographics, the rise of computer technologies, and chronic underfunding, as well as changing expectations for libraries in light of a growing dependence on computer technologies [2-7]. For many rural young people, their school libraries are their primary libraries and are therefore a dominant feature in the library literature concerning school and public library cooperation in rural areas [8-10]. Additionally, there are several articles that describe and evaluate specific, local rural library services [11-14]. In general, LIS offers an account of library services under the effects of various external pressures [15] as well as descriptions of the demographic characteristics of adult users [16], but we learn little about the meaning that libraries have in their rural communities or for their rural constituents.

The work reported here is informed by the cultural turn in geography, particularly by what is called the "new cultural geographies" influenced by British cultural studies. According to Denis Cosgrave, new cultural geography is "more concerned with space and spatiality than with environment and material landscape" [17, p. 136]. The related emphasis on human subjectivity, identity and territory, communication, social group formation, and the uses that social groups make of space marks this approach to space and spatiality as distinct from conventional themes of cultural geography concerned with "modes of agrarian life and human conduct of all kinds 
that bears upon human occupancy and geographical diversity apparent in landscapes" [17, p. 135]. In this study I explore the spatial dimensions of reading in a nonurban locale as a way to understand, following cultural geographer Gill Valentine, the ways in which these dimensions are "invested with certain meanings, how these meanings shape the way these spaces are produced and used, and, in turn, how the use of these spaces can feed back into shaping the way in which people categorize and identify themselves" [18, p. 5]. A framework informed by cultural geography helps to ask certain questions in this study: Why do spaces of reading have so little visibility in the daily media environments of young people? Are reading practices "inherently spatial" $[18$, p. 5] in that they depend on particular spaces for their construction?

The rural is typically conceived as a distinct, bounded space that is different from both suburban and urban life. Much research has focused on the extent to which perceptions of the rural idyll compete with the notion of rural life as isolating and remote from urban experiences. There is even debate as to whether the term "rural" has any meaningful significance in today's world given what some see as rampant urban imperialism and the global reach of mass media [19, p. 6]. Within the study of rural geography, questions are also asked about the ways in which the rural environment is transformed by various technologies. For example, Gill Valentine and Sarah L. Holloway examine the extent to which communication technologies such as the Internet and computers have overcome barriers of distance and isolation among youth in a small British rural area [20].

In this study, the blurred distinctions between rural and urban life lead to questions about the degree to which young people's engagement with print culture in small town and rural contexts is unique. Consideration must also be given to material aspects of access, such as the number and location of sources of books and other kinds of reading materials, such as libraries, bookstores, and other retail outlets. Other significant factors to be considered in a rural geography of reading include the availability of access to computers and to the Internet, as well as the levels of mobility of young people to be able to travel to and from such sources. Where do reading events and other kinds of evidence of an active reading culture occur in the rural community?

Geographies of young people emerged as a response to the apparent invisibility of children and young adults in research heralded by the humanistic turn in geography. An influential review essay by Chris Philo [21] suggests that rural studies should be renewed with attention to the geographies of rural people as experienced "from within" their own experiences. The result of these research currents is a still ongoing movement to write children into studies of space and place, with a related interest in 
investigating the exclusion of young people from adult public space as well as close consideration of the ways in which young people produce, appropriate, and navigate public and private space.

There have been several recent studies that consider multiple dimensions of the geographies of rural youth. For example, Cheryl Morse Dunkley researched young rural Vermonters living along the Canadian border, for whom various spatial factors converged to encourage risky behaviors such as drinking and driving [22]. Johan Fredrik Rye examines how rural Norwegian teenagers respond to competing concepts of "rurality" [23]. Anne Sofie Laegran juxtaposed the ways teenagers used two different "technospaces"-the gas station and the Internet café [24]. Michael Leyshon provides one of the few methodological papers on fieldwork with young people in rural areas [25]. Chris Philo and Fiona M. Smith argue for childoriented political geographies of children, claiming that children are usually overlooked in such studies because "children do not vote and have little influence on "political phenomena" [26, pp. 103-4]. Valentine and Holloway use cultural geography to frame their study of the use of information and communication technologies by rural young people [20]. Despite these studies and a handful of others like them, according to Dunkley, "Little is known about the everyday, lived geographies of youth living in rural America, particularly the obstacles 'rural' teens face in generating social opportunities and the strategies they face in overcoming such obstacles" [22, p. 560].

An engagement with print culture and the promotion of positive reading habits support the social and educational opportunities of youth. Geographies of children and youth help situate reading practices in a specific time and place for a specific cohort of young people coming of age in the early years of the twenty-first century. In this study of rural teens and reading, the framework provided by cultural geography permits a focus on how youth's perceptions and experiences are spatially structured through their engagement with print culture.

\section{Research Setting}

Between November 2006 and March 2007, interviews were conducted with twenty-seven young people who were between the ages of fifteen and nineteen years and who lived in or near a rural municipality in southwestern Ontario, Canada. The municipality contains a single small town that in 2001 had a Canadian census population count of 4,452, comprising approximately 45 percent of the total municipal population [27]. The remainder of the population is scattered throughout the surrounding farmland and among several villages. The only secondary school in the 
municipality is located in the town, as is the only full-service public library branch. ${ }^{3}$ In 2001 the municipality had 745 people between fifteen and nineteen years of age; 370 were male, and 375 were female. Forty percent of young people in this age range live in the town. Seventy-two percent of youth were in school full-time [27].

The nearest urban area has a population of just under 350,000 and is approximately thirty miles away. There is one small Christian bookstore, and for a few months there was one small used bookstore. A sparse selection of magazines is available at most variety and grocery stores. There are several hockey arenas and sporting grounds, one hospital, and several churches. There are no shopping centers, although there are stores that sell clothes, sporting goods, groceries, and sundry items. There are a number of casual food shops and restaurants. At the time of data collection, there were no music stores, cinemas, Internet cafés, or discernible dedicated teen-only spaces.

The municipality is predominantly Christian; most people reside in families and in homes that they own. Ninety-one percent of the population are native English speakers, and 10 percent were born outside Canada. Just over 1 percent of the population declare themselves to be visible minorities, and most people are of English, Scottish, German, or Irish ancestry. Statistics on the larger county population indicate that 40 percent of the working population do not have a high school diploma, suggesting a large blue-collar workforce. Yearly family incomes are, on average, about $\$ 10,000$ less than those of families provincewide [27]. The larger county, of which the municipality is a part, is considered to be one of the most agriculturally productive areas in Ontario. It has more farms, more farmland, and more gross farm receipts than any other county in the province. Manufacturing, tourism, and agriculture make up the three economic pillars of the county [28].

This municipality was selected as the research site because it provides a useful sample of young people with approximately equal numbers of youth living in the single small town and in the surrounding areas, as well as an approximately even split of male and female youth between the ages of fifteen and nineteen years. Also, the location of a single full-service library branch in the only town allows for a concentration of research activities in one place. The municipality is also geographically near to a large city, which allows for an examination of its status in the periphery of urban structures that affect the distribution of print culture and products.

3. There is also a one-room library branch in a village on the western boundary of the municipality. It is telling that not one of the participants, including a young man who lived in the village, knew that it was there. 
Research Method and Procedures

This research is an in-depth exploration of the reading practices of rural and small-town youth, in an effort to understand more fully their everyday engagement with print culture as exhibited through practices associated with voluntary reading habits, public library use patterns, bookstore visits, and uses of the Internet. Since the research objectives were to look at the lived experience of reading among rural youth and to explore the meanings that emerge from their experiences, this inquiry is guided by qualitative research methods. Access to reading materials through public and school libraries, online bookstores and other retailers, online public-access library catalogs, online news sources, blogs, and any other electronic and digital sources of reading material as identified by participants themselves are examined.

Data Collection

Data collection occurred in a single rural municipal area, with the use of a range of methods. Gaining access to the research field began in the summer of 2006 after an extensive literature review and ethics approval from the institutional review board at the University of Toronto. The primary method of data collection was the use of conversational, in-depth interviews with youth between the ages of fifteen and nineteen years. As the sample of participants is diverse-including youth who like to read a lot, youth who like to read a little, and youth who do not enjoy reading at all-interviews enabled responsive questioning tailored to the unique context of each face-to-face interaction. The interviews ranged in duration from twenty to sixty minutes. In keeping with guidelines for this kind of interviewing, a uniform schedule of interview questions was not used; instead, as the interviews progressed, I developed a series of salient "hermeneutic prompts" [29], an interviewing strategy used successfully in other research [30]. I conducted all interviews in face-to-face encounters at mutually convenient times. Informed consent was required for all interviews, and interviews with minors occurred only with the additional written consent of parents or guardians. All interviews were audiorecorded and transcribed.

Unobtrusive Participant Observation and Environmental Scans

Data about reading practices were collected using unobtrusive participant observation at the school, at public libraries, and at retail stores that sell reading materials. Specific interviewees were not observed, but observation sessions were conducted to monitor the activities that occur within relevant sites in this municipality. The observation sessions were limited to those 
sites where my presence as an adult "outsider" was publicly credible. Another source of data for this project came from several environmental scans of the municipality to gain an understanding of the kinds of cultural products and events that were available and accessible during the period of data collection. Between May 2006 and August 2008, I made thirty visits to the municipality to conduct interviews, as well as to scan the shelves at libraries and at various retailers that sold reading materials and media products. Furthermore, ten observation sessions were conducted at the public library, along with eight sessions at the high school library.

\section{Sample of Participants}

Purposive sampling was used because it allows for emergent sampling design, the serial selection of sample units with continuous adjustment, and the selection of sampling to redundancy of categories [31, pp. 201-2]. Snowball sampling was rejected, as it reduces the degree of confidentiality that could be ensured for participants. Multiple sites were used to gain access to young people, including the high school and public libraries, recreational centers, post offices, and retail stores. Access to youth participants was negotiated through adult gatekeepers, including the regional school board administration, the high school principal, teachers, and the teacher-librarian. Information letters for youth participants, adult gatekeepers, and parents or guardians were distributed through classroom visits and via the school and public libraries. Fourteen participants were female and thirteen were male, and the median age was seventeen years. All participants were white, and most had lived in or near the municipality for all or much of their lives. Approximately 18 percent of the participants resided in the single small town. Demographic data related to the income and education levels of participants' parents were not collected: the purpose of this study is to learn about the nature of reading and libraries and their meaning in the lives of rural young people rather than to make generalizations about rural youth. When asked, approximately 56 percent of participants said they saw themselves as readers, and 44 percent said they saw themselves as either nonreaders or light readers. In recognition of the value of their time, participants were given $\$ 20$ gift certificates from stores located in the nearest city.

Data analysis was guided by open-coding techniques [32] and involved the qualitative procedures of active listening, immersion in the data, data reduction and transformation, and thematic analysis [33, pp. 76-82]. These procedures correspond to the "constant comparative method" of grounded theory techniques, by which close attention is paid to the data to see which themes emerge [32]. Strategies of peer debriefing (with other LIS and 
youth researchers) and member checking (with participants) were used to test the salience of the ongoing thematic analysis. ${ }^{4}$

Thematic Findings: Spatial Dimensions of Reading

Four main themes that correspond to spatial dimensions were developed through the coding exercises: the role of physical proximity and everyday access to reading materials, the shifting valence of visibility of the public library in the daily landscape of these youth, the role of the Internet as a taken-for-granted place for reading, and the consistently articulated lack of space in time for reading.

Theme 1: Physical Proximity and Everyday Access to Reading Materials

Very few of the participants invested time in searching for reading materials, even those who identified themselves as people who read a lot and who "love" to read. The single most common way that printed reading materials such as books, magazines, and newspapers made it into the hands of the young people in this study was by physical proximity-they quite literally came across the materials in the course of their day. For example, even though he claimed he was not a "big fan" of reading books, sixteenyear-old Tim said, "Wherever I see it, I'll grab a copy and look at it and just look at it for a bit." ${ }^{5}$ Several other participants echoed this sentiment when asked to describe how they chose materials to read. Although eighteen-year-old Brent declared that he was "not much" of a reader, he gave repeated evidence of various reading interests, but perhaps he was simply reflecting his brother's reading preferences, as raiding his brother's closet was the primary way that Brent found something to read: "I was just looking in my brother's books and I picked it out." William, fifteen years old and a light reader, simply made choices from the selections in his home: "We have a lot [of books] already so I just pick one that I like." However, even for participants who described searching for "something good to read," the most active kind of searching can only be described as browsing. While serendipitous encounters with reading materials along with casual browsing and borrowing are certainly common methods for finding reading materials, questions are raised about what happens when such methods do not yield any satisfying results.

Other reading research has found that other people are frequently seen as trusted sources for reading recommendations [34]. This is borne out

4. For aid with qualitative coding of the transcribed digital texts in an Apple computing environment, I used TAMS Analyzer Software, version 3.4, created by Matthew Weinstein.

5. All names of participants have been changed. 
by the research reported here: when asked how they found reading materials, participants also frequently mentioned family members, teachers, and, less often, librarians-people they encountered and interacted with on a near-daily basis. Factors of everyday proximity and personal recommendation interact to produce a positive outcome (i.e., "something good to read"), but the method of finding a book to read remains a passive activity.

Furthermore, in this sample, friends were not viewed as a source of reading recommendations. Many of the readers in this study saw themselves as being somewhat unique and alone among their peers in terms of their identity as readers. When asked whether they shared reading preferences with their friends, most participants responded indirectly by saying things like, "They're not really big readers" (Lisa, fifteen years old); "Not really as much as me, not even close" (Allison, sixteen years old); and "The odd friend, but not really. . . . Not really. Like, I know my friends don't [read] as much. I don't really recommend [books]—maybe to my brother or something" (Katherine, seventeen years old). Many young people simply responded with an emphatic no when asked whether their friends were readers. The following exchange with Lena, an eighteen-year-old voracious reader of historical fiction, gives evidence of the negotiated meaning of reading among friends.

PR: Are your friends readers too?

Lena: A few of my friends are very much religious so I read The Da Vinci Code. I'll put out my views and they basically kind of shunned me when I talked about my views because [my views] don't agree with most of theirs. Usually, if we get onto that topic we finally kind of just said, "Alright, this is my opinion, that's your opinion."

$P R$ : Are there other books that aren't like that, that are safe?

Lena: There are no safe ones when you talk about books. You're gonna get your opinions out and some of them are gonna be a little more radical than others.

Daily interaction with friends was clearly the norm with these young people, but friends were not identified, implicitly or explicitly, as sources of reading material or as partners in reading activities.

On the one hand, it may seem to be a positive phenomenon that young people are finding reading materials everywhere with little effort, as it may suggest a rich reading culture where reading materials are plentiful. On the other hand, the aspect of "little effort" itself can be troubling, as there is scant evidence in this data to show that young people are exerting any effort to find reading materials, even when they see themselves as readers. This renders a readership that is dependent on whatever the field can provide, whatever reading materials surface as these young people move 
through their everyday environments, thus raising important questions about how and what materials are distributed.

Theme 2: Shifting Visibility of the Library

The young people in this study conceive of libraries in three main ways: as places to use computers, as places of childhood, and as negative spaces defined by what they do not offer. Libraries take on a shadowy presence made visible in their potential to provide access to information through Web-enabled computers, in memory, and in negative definition of what they offer to young people living in the municipality.

Many participants visited both the school library and the public library to gain access to computers for help with school assignments. When asked about their usage of libraries, participants gave answers consistent with those of eighteen-year-old Leah, a light reader who said that when she uses the school library, "I'm mostly on the computer," and of fifteen-year-old Jennifer, a heavy reader who uses the library "to do research and stuff." Many students found themselves on the computers during breaks in their classes, taking advantage of unstructured time to use the computers in the school library. For example, Tim told me that he uses the school library only "for the computers. When I have my spare [period] I'll come in, maybe do some homework, stuff like that." Eighteen-year-old Ryan, a young farmer, did not read for pleasure or entertainment because he had no time in his busy schedule and felt it was waste of his time. It is no surprise that he capitalized on a spare period in his class schedule to use the computers for help with his homework: "I come here every day. I have a spare right now so I come here and do homework. . . . Usually when I want to find information on something it's easier just to go [to a computer] and type it in instead of finding a book through here [points to shelves]." Similarly, Michael, a seventeen-year-old skilled computer programmer, took advantage of the proximity of the school library for access to both computers and books: "[I use the school library] fairly often, yeah. Mostly for research and for access to the computers. . . . I can't say that I use [the public library] very much . . . for books that I can't get here." It is, perhaps, sixteen-year-old Joe's comments that underline the role of the library as a default avenue for access to computers. He was an avid reader who made most of his reading selections from his mother's personal library of novels and rarely used either the school or public library, but when asked about the last time he used the library, he replied, "I do recall the last time I was there. I think my computer broke, so I had to use the computer there." These excerpts give evidence that the library does take up a place in the everyday information and reading environments of youth, but its significance is tempered in their accounts, rendered invisible perhaps by an instrumental perception of it as a place to get access to computers. 
A number of participants spoke about the public library as a place that had more relevance for them when they were younger. They were eager to share happy recollections of their visits to public libraries, usually with family members. For example, Joe recalled that he used the public library "more so when I was younger than now. My mom used to bring us there once in a while just to get little books." Ryan told me that he was a regular public library user when he was "like six, seven years old" and that it was "a long time ago" since he last used it, which would have been at least eleven years ago. Darren, who thought that Harry Potter was the last book he read that he enjoyed, elides library usage and reading in his succinct response when he replies that he "used to [use the public library], but not anymore. [I was] younger-I used to read books." Darren read almost exclusively online at the time of our interview. Throughout the interviews there is a persistent theme that the library was a place of childhood. These recollections give evidence of the dynamic role that the public library played in their lives, but it is challenged by their competing commentary on what the library offers to them as they come of age.

The library was also defined by what it does not provide, whether books, technology, access, or space. Joe might have considered using the public library computers for homework, but he told me that he used it "rarely: they don't allow [you] to download things, to put it on remote media." He rejected the school library because, from his perspective, "they don't have a big selection of books." Similarly, William discounted the libraries in the municipality because they were not seen to carry materials to support his interest in computer programming: "I'm generally looking for-well, I look for programming languages and Windows hacks, like where you can change it. I always look for Linux books but they don't have those much in the library." Ruth, a fifteen-year-old young woman who lived outside town and who was heavily involved with her church, held the same view of the public library in her search for Christian fiction. After describing how she sometimes purchased books at the local Christian bookstore, she went on to say, "They're just hard to find, the certain [titles] that you want. You can't just go to the public library and get them." A final example from the interviews clearly illustrates how the lack of access trumps all other reasons for not using the public library. When asked about his public library usage, Ryan earnestly responded, "I try to [use the public library] but they're closed all the time. They have weird hours. They're the least accessible hours for anyone who's a student. . . . I used to go to school in [the city], and by the time I got home the town library was closed. I never really used it." The tension in this response related to what seems to be an authentic desire to use the library, but one that is confounded by its hours of operation, is echoed throughout this study. His response throws into sharp relief the spatial dimensions of library use (and nonuse). His 
daily removal from the municipality to attend a school in a neighboring city and the requirement of being transported between his home and school eat into the time available to him to visit the library, and the hours kept by the library foreclose any fruitful interaction with it. The limited collection and hours of the school library do not make it a viable alternative, and the sheer lack of any other alternatives makes the Internetenabled home computer the only source of information for homework and for reading materials beyond the best sellers and magazines available at the local stores. However, overall, on the basis of evidence from the interview data, this young man is like the others in the study in not exercising an a priori rejection of the library as unsuitable or inappropriate; rather, there is a subtle yet strong articulation of its failure to take account of their needs. Furthermore, regardless of perceptions of school and public libraries, the institutions take a central place in the participants' stories of reading and media use whether they see themselves as avid readers or not.

\section{Theme 3: The Internet as a Default Place for Reading}

For many of the participants, the Internet is conceived of as both a place and a tool for finding information. It is also a medium that allows them to communicate with friends, although there was pointed criticism of popular social networking sites such as Facebook and MySpace. The Internet itself is considered a place to go to do something, to hang out, and to locate reading materials. Given the importance of quotidian encounters with reading material, it is no surprise that the sheer physical proximity of the Internet-enabled computer positions it as a default source of reading materials and place for reading practices. Reading can be located in the context of Internet use along two dimensions: these young people are already there in front of the screen, in the household, in a family computer room, or in a bedroom, but participants are also already online, in "cyberspace." When asked about online reading, most participants spoke about it as a fairly random process of coming across information that prompts them to read further, much as how seeing a magazine in the school library prompts them to pick it up and read it. Shelley, an eighteenyear-old high school senior with plans to become a teacher, was interested in reading about stem cell research. She gave an example of how she reads online: "I have a pop-up that comes up and says 'Recent News and Developments' and . . . if it interests me I'll click on it. . . . Even if you just, like, Google, like, some pictures, what you're interested in, it usually leads to a nice article." Harvey, seventeen years old and an avid reader, uses the same strategy for online reading, telling me, "I'm on my computer mostly, mainly just because it's there, it's hooked up to the Internet," and "I have an MSN page where I get news, so if I see something interesting on the news, then I'll go and read." Darren illustrates the taken-for-granted di- 
mension of online reading habits after telling me that reading plays a "pretty big" role in his life: "I go on the Internet, like, every night to read. . . . Kind of like a habit: every night, I go home, go to the computer, read stuff. Any time I find the time. Just whenever I walk in.” Reading using computers and the Internet is revealed as a daily practice that is hardly counted as reading, and yet nearly all participants reported spending a significant amount of time with online texts.

Most participants were not avid users of social networking sites. Inconsistent and unreliable access to the Internet may explain some of their disenchantment, as powerful computers and fast Internet connections make using such tools much more enjoyable and efficient. Lack of time for use of the Internet for entertainment activities may also play a role in their expressed low interest in these kinds of Web sites. For example, when I asked Brent about Facebook, he replied, "I don't agree with those. Like, I'm not against them, I just wouldn't do that. . . . It just seems like a waste of time to me. I don't know. And it's kind of weird, I think, putting all your information out there. What if people spy on you?" Discussion of media use is outside the scope of this article, but this comment reminds us to question the pervasive representation of young people as enthusiastic and uncritical adopters of online media tools.

\section{Theme 4: Lack of Space in Time for Reading}

One of the most dominant themes in this set of data has to do with repeated articulations regarding the temporal constraints on reading: almost all participants indicated that they do not have enough time to read. This was not a surprising finding, as previous studies of teens and reading have yielded similar results $[35,36]$. The simple accounting of time indicates that there is little space in the schedules of most teenagers for reading activities. The connection between liking to read and finding time to read is illustrated by the following excerpts:

I wouldn't say [I] hate to read, but I find I don't have a lot of time to actually read. A lot of [the] time I read, like, newspapers and stuff like that. . . . I also have a hard time finding books that I like. . . . I do a lot of extracurricular activities, lot of volunteering. I play two sports-I play hockey and curling. I do that basically every night. [By the time I get home] I basically just do my homework. (Leah, eighteen years old)

I'd definitely be one of those people who don't like to read a lot. Like, I'd probably like to read more. . . . I'll start books but I won't finish them. And I just don't know what it is, but . . I I just kind of forget about it. Like, it's-like, you want to read it but you don't find the time. (Daniel, seventeen years old)

Both Leah and Daniel identified as people who would read more if they had more time. They were able to speak easily about books that they had 
read and enjoyed in the past, and both expressed a desire to read more for their own pleasure. Like others in this study, they recounted the activities of their nonschool hours-paid employment, required volunteer work, and extracurricular commitments related to sports, music, and church, along with family responsibilities, homework, and spending time with friends-that made reading for pleasure a near impossibility except for the most motivated of readers.

The young people in this study perceive the lack of time as a serious barrier to enacting reading practices outside school-based needs. However, the data also show that reading practices, including searching for reading materials, constitute a major portion of the daily activities of these young people.

Discussion: The Placelessness of Reading

The young people in this study are spatially isolated from a rich print culture because of their geographic location in a rural area that supports very few sites of access to reading materials. Their reading choices are constrained by a lack of formal or informal sites from which to make selections. The actual physical places that support voluntary reading are few. This apparent placelessness of reading is deepened by the failure to locate places of reading that are produced through social interactions, such as communities of readers or reading events. The concept of the library as place emerges in this research as an abject place, defined by perceptions of what it does not offer or does not provide to the young people in the study.

My participants exercised reading choices simply by moving through their everyday environments and encountering a wide though shallow array of reading materials in both printed and digital formats. There are few signposts by which to navigate in this everyday environment, and reading choices are formulated on the basis of availability, cost, and convenience. The everyday nature of these encounters with texts cloaks their significance, making them difficult to articulate or recount. Furthermore, the heavy demands on time in the out-of-school lives of my participants push almost all reading practices even further into the shadows of mundane experience. The library's perceived inadequacy is fixed in place by memories of earlier experiences, whether it is thought of as a place for childish reading or as a place that offers little to support the active interests and needs of youth today. The youth in this study are further denied access to a rich print culture because their reading experiences, especially those in an extracurricular context, occur largely in isolation from either other reading experiences or other readers. The lone teen reader is the norm in this sample: there were almost no shared experiences of reading offered by participants. This is not to say that there were no opportunities for 
communal book discussion; there were some, but these were limited to an occasional lunchtime book group in the school library and to a faith-based reading group sponsored by a local church. ${ }^{6}$

There is also little evidence that reading or reading materials are a source of everyday conversations inside or outside the home. Following Roger Silverstone, Eric Hirsch, and David Morley [37], who have studied the ways in which information and communication technologies get domesticated in everyday life, neither reading itself nor the various texts that are read are providing links between households, between home and school or work spheres, or between individuals. Reading in this study is a solitary pursuit in which there are few opportunities for articulating reading interests and reading experiences beyond the encounter that an individual has with a text itself. If the idea of the teen reader depends on particular spaces for its construction, what spaces exist in this community to produce teen readers? One consequence of a contracted reading ground is the production of the nonactive teen reader: the limited reading choices found throughout the municipality combined with few opportunities to enact a reading identity make the concept of the teen reader unviable. Just as the concept of reading is not embedded in the wider sphere of the community, neither is the youth reader. Despite evidence of a reasonably robust selection of reading materials for young people in both the physical and online realms, this municipality suffers from an impoverished print culture that, in turn, gives rise to a concept of the "nonreading youth," an embodied space made visible at the geographic scale of the body [18, pp. 15-60].

The static embodied space of the nonreading youth is potentially undermined by the evidence in this study of habitual and daily enactment of reading practices-for example, visiting libraries for access to computers and reading materials, texting a best friend, browsing the magazine section at the variety store, reading the headlines in a Web browser, and so on. However, this is not to say that reading experienced in this way is insignificant or trivial. The concept of "place choreography," first put forward by phenomenologist geographer Derek Seamon [38, pp. 54-59] and resurrected in recent years by media scholar Shaun Moores [39, 40], provides a framework for bringing meaning to these daily exercises related to reading and information seeking. Senses of place are fostered by what Seamon originally called "place-ballets" in his study of the everyday movements of the members of his environmental experience group [38, p. 163]. Placeballets are conceived of as the interaction of what Seamon terms "timespace routines" and "body routines" in a supportive physical environment

6. While they are outside the scope of this article, there are tentative findings that suggest that youth with strong religious affiliations exhibit a deeper engagement with a print culture that emerges from faith-based reading and access to church libraries. 
[41, pp. 3-4]. A body routine is "a set of integrated gestures, behaviors, and actions that sustain a particular task or aim, for example, preparing a meal, driving a car," and a time-space routine is a set of habitual actions that "extends through a considerable portion of time" [41, p. 3]. By recreating and recalling daily movements through time, Seamon suggests a threefold structure composed of "movement," "rest," and "encounter" as a conceptual means to understand a specific environmental experience [41, p. 11]. Movement is the habitual nature of everyday experience examined at the level of routine bodily movements, such as driving to work, or morning rituals-movements that we pay little attention to in our conscious states and yet perform consistently throughout our day. Rest refers to people's affective relationships with environments that allow us to feel "at home," and the concept of encounter encompasses the ways in which people make what Seamon calls "attentive contact" with their surroundings [41, pp. 2-3]. This conceptual framework provides a means for making sense of the daily, habitual reading practices of the young people who participated in this study; further, it gives a way to privilege these reading practices rather than to discount them as insignificant. In this framework, then, the time-space and body routines of young people-as described in their accounts of happening upon reading materials in a variety of daily contexts, of logging on to the Internet to read, of giving the library a space of significance even through a basic rejection of its usefulness, and, finally, of managing reading practices in a competitive schedule of other commitments-give weight to the idea that reading practices occur at the level of "movement" constituting the habitual nature of everyday reading. But, importantly, the placelessness of reading discussed earlier suggests that this kind of reading still needs to find a supportive physical environment in this municipality and that, in order for it to be a supportive environment, young people need sites that also support the notions of rest and encounter in the context of reading behavior. In other words, the reading is in place, but there are few means for place-ballets to flourish, and this is where the public library could play the strongest role. The library is already awarded a place of significance in the lives of the rural young people in this study; all kinds of reading activities are already a significant part of their lives. The library holds the potential of becoming an important place of "interpersonal and communal exchanges, actions, and meanings" [41, p. 4] in support of an active reading culture for youth. 
Conclusion

The research reported here makes a contribution to LIS studies of rural libraries and librarianship by providing a sustained theoretical analysis of the place of the public library among youth coming of age in a specific rural municipality. This study responds to a recent trend in LIS research, as it shares a concern to understand the physical place of the library in the everyday environments of its clientele, seeking to understand not only how it is used by people but also the symbolic meaning that it holds for them [1]. Rural, cultural, and youth geographies directed the analysis of interview data to a serious consideration of the spatial dimensions of both reading and library practices and how they interact, with an understanding of not only the teen reader but also how young people make use of and understand such spaces. In this article, I have identified four spatial factors-the role of physical proximity of reading selections in the everyday lives of young people, the default place of the Internet as a site to make and enact reading choices, the public library as a place of childhood reading and as a place evaluated by what it does not offer, and the lack of time in space for reading. These spatial factors converge to render both what I have theorized as the nonactive teen reader and the placelessness of reading as a way to reconcile the scant visibility of an active reading culture in this municipality with the evidence of pervasive daily reading practices in the everyday lives of the young people. The multidimensional isolation of the teen reader produces the space of the nonactive teen reader, which in turn defeats any projects to anchor a vital reading culture-this despite evidence that youth are reading and making reading selections throughout their day as they move through their local environments. This contributes to the placelessness of reading, a phenomenon that emerges through an examination of several factors: the geographic dislocation of young people from active and easily accessible fields of print culture, the invisibility of physical places that support readers and reading events, and little evidence of the production of communities of readers through the reading of shared texts. However, an examination of the place of the library, both in the reading lives of rural youth and as a central source of reading material in this municipality, shows it to be much more than a static storehouse of materials or a channel for the Internet. The library carries the capacity to capitalize on its place of significance and function as a local site that can foster a lively and engaged reading culture for youth. 


\section{REFERENCES}

1. Leckie, Gloria J., and Buschman, John E. "Space, Place, and Libraries: An Introduction." In The Library as Place: History, Community, and Culture, edited by Gloria J. Leckie and John E. Buschman, pp. 3-25. Westport, CT: Libraries Unlimited, 2007.

2. Wigg, Ristiina. "Across Towns and across Times: Library Service to Young People in Rural Libraries." Library Trends 44 (1995): 88-111.

3. Sheller, Becky. "Kids Are the Issue: Rural Libraries and Children's Services." Rural Libraries 3 (1983): 95-111.

4. Johnson, Linda. "The Rural Library: Programs, Services, and Community Coalitions and Networks." Rural Libraries 20 (2000): 38-62.

5. Walton, Susan P. "Programming in Rural and Small Libraries: An Overview and Discussion." Rural Libraries 21 (2001): 7-23.

6. Smith, Erin LeAnn. "Why Rural Public Librarians Should (and How They Can) Serve Young Adults." Rural Libraries 23 (2003): 45-68.

7. Conway, Susan M. "Young Adult Public Library Services: An Overview." Rural Libraries 25 (2005): 37-58.

8. Mautino, Patricia. "The Implications of Networking on School-Public Library Cooperation in Rural America." Rural Libraries 1 (1980): 11-47.

9. Jackle, Barbara E. "Book Borrowing Habits of Urban and Rural Children: A Survey." Rural Libraries 4 (1984): 1-19.

10. Minnick, Michelle. "An Investigation of Library Services Offered to Kindergarten Students in Rural Public Schools in Washington County, Pennsylvania." Rural Libraries 21 (2001): $37-54$.

11. Shilts, Carla. "Day Care: A New Role for the Rural Public Library?" Rural Libraries 8 (1993): $67-79$.

12. Riley, Joanne M. "Dragon Seeds: Programming for Children in Rural Libraries." Rural Libraries 5 (1985): 26-34.

13. Harris, Kimberley D. "Lost and . . . Found? Children in the Rural Library." Rural Libraries 19 (1999): 30-36.

14. Drescher, Judith A. "Outreach and the Public Need." Rural Libraries 17 (1997): 43-50.

15. Knight, Robert. "Last One out Turn off the Lights: The Influence of Geographic, Demographic and Economic Factors on the Provision of Library Services in Rural and Remote Communities." Rural Society 12 (2002): 273-84.

16. Vavrek, Bernard. "Rural Information Needs and the Role of the Public Library." Library Trends 44 (1995): 21-48.

17. Cosgrave, Denis. "Cultural Geography." In The Dictionary of Human Geography, edited by R. J. Johnson, Derek Gregory, Geraldine Pratt, and Michael Watts, 4th ed., pp. 135-36. Malden, MA: Blackwell, 2000.

18. Valentine, Gill. Social Geographies: Space and Society. Harlow: Pearson Education, 2001.

19. Bonner, Kieran. A Great Place to Raise Kids: Interpretation, Science, and the Urban-Rural Debate. Montreal: McGill-Queen's University, 1997.

20. Valentine, Gill, and Holloway, Sarah L. "A Window on the Wider World? Rural Children's Use of Information and Communication Technologies." Journal of Rural Studies 17 (2001): 383-94.

21. Philo, Chris. "Neglected Rural Geographies: A Review." Journal of Rural Studies 8 (1992): 193-207.

22. Dunkley, Cheryl Morse. "Risky Geographies: Teens, Gender and Rural Landscape." Gender, Place, and Culture 11 (2004): 559-79.

23. Rye, Johan Fredrik. "Rural Youths' Images of the Rural.” Journal of Rural Studies 22 (2006): 409-21. 


\section{READING AMONG RURAL CANADIAN TEENS}

24. Laegran, Anne Sofie. "The Petrol Station and the Internet Café: Rural Technospaces for Youth.” Journal of Rural Studies 18 (2002): 157-68.

25. Leyshon, Michael. "On Being 'In the Field': Practice, Progress and Problems in Research with Young People in Rural Areas." Journal of Rural Studies 18 (2002): 179-91.

26. Philo, Chris, and Smith, Fiona M. "Guest Editorial: Political Geographies of Children and Young People." Space and Polity 7 (2003): 99-115.

27. Statistics Canada. "2001 Community Profiles." Catalog no. 93F0053XIE. Statistics Canada, Ottawa, 2002. http://www12.statcan.ca/english/profil01/CP01/Index.cfm.

28. Hopkins, Jeffrey. "Signs of the Post-rural: Marketing Myths of a Symbolic Countryside." Geografiska Annaler: Series B, Human Geography 80 (1998): 65-81.

29. van Manen, Max. Researching Lived Experience: Human Science for an Action Sensitive Pedagogy. London, ON: Althouse, 1990.

30. Rothbauer, Paulette M. "Finding and Creating Possibility: Reading in the Lives of Lesbian, Bisexual and Queer Young Women." PhD diss., University of Western Ontario, 2004.

31. Lincoln, Yvonna S., and Guba, Egon G. Naturalistic Inquiry. Newbury Park, CA: Sage, 1985.

32. Strauss, Anselm, and Corbin, Juliet. Basics of Qualitative Research: Techniques and Procedures for Developing Grounded Theory. 2nd ed. Thousand Oaks, CA: Sage, 1998.

33. Cohen, Marlene Zichi; Kahn, David L.; and Steeves, Richard H. Hermeneutic Phenomenological Research: A Practical Guide for Nurse Practitioners. Thousand Oaks, CA: Sage, 2000.

34. McKechnie, Lynne (E. F.); Ross, Catherine S.; and Rothbauer, Paulette M. "Affective Dimensions of Information Seeking in the Context of Reading." In Information and Emotion: The Emergent Affective Paradigm in Information Behavior Research and Theory, edited by Diane Nahl and Dania Bilal, pp. 187-96. Medford, NJ: Information Today, 2007.

35. Hughes-Hassell, Sandra, and Lutz, Christina. "What Do You Want to Tell Us about Reading? A Survey of the Habits and Attitudes of Urban Middle School Students toward Leisure Reading." Young Adult Library Services 4 (Winter 2006): 39-45.

36. Marra, Tiffany, and Witteveen, April. "Survey Says . . . Trends in Teen Reading, 2001-2003." Young Adult Library Services 4 (2005): 17-21.

37. Silverstone, Roger; Hirsch, Eric; and Morley, David. "Information and Communication Technologies and the Moral Economy of the Household." In Consuming Technologies: Media and Information in Domestic Spaces, edited by Roger Silverstone and Eric Hirsch, pp. 15-31. London: Routledge, 1992.

38. Seamon, David. A Geography of the Lifeworld: Movement, Rest and Encounter. New York: St. Martin's, 1979.

39. Moores, Shaun. "Media Uses and Everyday Environmental Experiences: A Positive Critique of Phenomenological Geography.” Particip@tions 3 (November 2006), http://www .participations.org/volume\%203/issue\%202\%20-\%20special/3_02_moores.htm.

40. Moores, Shaun. "Media and Senses of Place: On Situational and Phenomenological Geographies.” Media@lse Electronic Working Paper no. 12. London School of Economics and Political Science, London, 2007. http://www.lse.ac.uk/collections/media@lse/ mediaWorkingPapers/ewpNumber12.htm.

41. Seamon, David. "A Geography of Lifeworld in Retrospect: A Response to Shaun Moores." Particip@tions 3 (November 2006), http://www.participations.org/volume\%203/issue\%202 \%20-\%20special/3_02_contents.htm. 